\title{
Pediatric Orbital Tumours in Upper Egypt: A 3-year Retrospective Analysis at a University Hospital.
}

\author{
Ahmad Mostafa Abdallah*, Mohamed Anber Abdellatif, Ashraf Mostafa Elhwary, Amin Abuali \\ Hassan, Ahmed Gad Kamel, Islam Saad El Saman, Islam Awny Ahmad
}

Department of Ophthalmology, Sohag Faculty of Medicine, Sohag University, Egypt

\begin{abstract}
Purpose: To evaluate the relative frequencies, clinical profile, and treatment outcomes of Pediatric orbital tumours in Upper Egypt.

Materials and Methods: In a retrospective, non-comparative, case series study, the authors reviewed the medical records of all children evaluated at Sohag University Hospital, from September 2014 till August 2017, with the diagnosis of orbital tumours and tumour-like lesions. The final diagnosis in each case was established by a combination of history, ophthalmic examination findings, imaging studies, and histopathologic examination if biopsy was performed.

Results: A total of 92 orbital lesions were included in this study, which were classified into the following major categories: Cystic (28 cases, 30.4\%), vascular (13 cases, 14.1\%), Lipomatous (10 cases, $10.9 \%)$, inflammatory ( 9 cases, $9.8 \%$ ), neurogenic ( 7 cases, $7.6 \%)$, lymphoid/leukemic (6 cases, $6.5 \%)$, myogenic ( 5 cases, $5.4 \%$ ), lacrimal gland ( 5 cases, $5.4 \%)$, secondary ( 4 cases, $4.3 \%)$, metastatic ( 3 cases, $3.3 \%$ ), and histiocytic ( 2 cases, $2.2 \%$ ) orbital lesions in order of frequency. The clinical features and treatment outcomes of these lesions will be discussed.

Conclusion: A variety of benign and malignant Pediatric orbital tumours may be seen in clinical practice. Management of these tumours requires a multidisciplinary approach. Early diagnosis and prompt treatment provide good cosmetic and functional results, and prevent visual loss in the majority of those children.
\end{abstract}

Keywords: Proptosis, Orbital tumours, Clinical diagnosis, Orbital imaging, Histopathology, Orbitotomy

\section{Introduction}

The spectrum of Pediatric orbital lesions ranges from those with typical external appearance such as capillary hemangioma, or typical location such as dermoid cyst; to those that present with axial proptosis such as optic nerve glioma, or with nonaxial proptosis such as rhabdomyosarcoma and lacrimal gland tumours [1-5]. Idiopathic orbital inflammation usually present with proptosis associated with diffuse or localized orbital inflammation of acute onset. However, some malignant orbital tumours in children, such as rhabdomyosarcoma, may present with acute proptosis which is associated with orbital inflammatory signs and symptoms [6,7]. A history of sudden onset of eyelid ecchymosis simulating ocular trauma, may occur with metastatic neuroblastoma in children $[8,9]$.

Proptosis is the hallmark of orbital diseases in both children and adults. It is considered as a diagnostic challenge requiring a detailed history, careful clinical examination, and the use of proper imaging studies. The physician who evaluates a child with proptosis should have a thorough knowledge about the various types of orbital tumours in Pediatric age group, their relative frequencies, and methods of diagnosis and treatment [10-13]. The reported incidence of orbital tumours varies widely from series to series, mainly due to the difference in the study population (e.g. children versus adults), and type of the survey (e.g. clinical versus histopathologic) [14-18]
To our knowledge, the present study is the first survey of Pediatric orbital tumours in our locality, represented by a tertiary university hospital in Upper Egypt. The authors included all consecutive Pediatric patients treated with the diagnosis of orbital tumours over a 3-year period, aiming to evaluate the relative frequencies, clinical profile, and treatment outcomes of these tumours.

\section{Materials and Methods}

In this retrospective non comparative case series study, the authors reviewed the medical records of all children (aged $\leq 16$ years), evaluated at ophthalmology department, Sohag University Hospital in Upper Egypt, from September 2014 till August 2017, with diagnosis of orbital tumours, aiming to clarify the relative frequencies, clinical profile, and treatment outcomes of these tumours in the Pediatric age group. The study was designed according to the principles outlined in the Declaration of Helsinki, and had been approved by the Health Research Ethics Committee at Sohag Faculty of Medicine. Also, written consents for examination, investigation, photography, and treatment options including surgery were obtained from the parents of those patients. Using the ophthalmology department database, the medical records of patients included in this study were reviewed for the following: age, sex, mode of onset and duration of the disease, site of 
Citation: Abdallah AM, Abdellatif MA, Elhwary AM, et al. Pediatric Orbital Tumours in Upper Egypt: A 3-year Retrospective Analysis at a University Hospital. J Clin Ophthalmol 2019;3(1):108-120.

orbital involvement, orbital imaging findings, clinical diagnosis, histopathologic diagnosis, and treatment modalities and outcomes. The final diagnosis in each case was established by a combination of detailed history, ophthalmic examination findings, diagnostic orbital imaging studies (CT and/or MRI scans), and histopathologic examination of the excised lesion if biopsy was performed. The collected data were grouped using a modification of a previously published classification of Pediatric orbital tumours by Shields et al. [19], into the following major categories: cystic, vascular, myogenic, neurogenic, lipomatous, lymphoproliferative/leukemic, lacrimal gland, secondary, metastatic, histiocytic, and inflammatory lesions. A diagnostic algorithm for Pediatric orbital tumours in this study is shown in Figure 1.

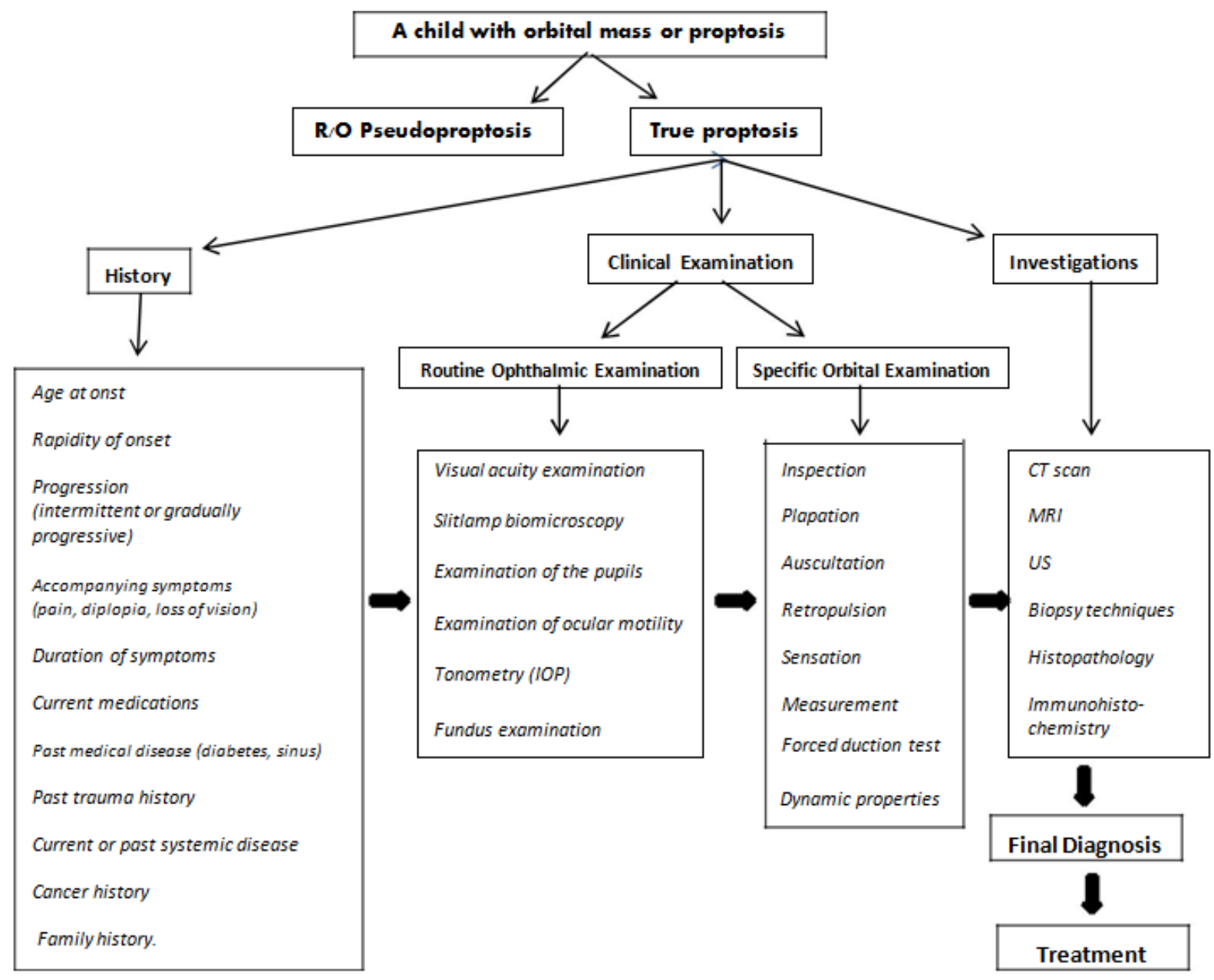

Figure 1: A diagnostic algorithm for pediatric orbital tumors in this study

\section{Results}

During a 3-year period from September 2014 till August 2017, a total of 92 Pediatric patients with diagnosis of orbital tumours and tumour-like lesions were evaluated at ophthalmology department, in Sohag University Hospital. The general demographic data of those patients are shown in Table 1. The number and percentage of lesions in each major category are shown in Table 2 . The number and percentage of individual orbital tumours in this study are shown in Table 3. The main presenting clinical features for orbital lesions in each major category are shown in Table 4.
Table 1: Demographic data of 92 children with orbital lesions in this study

\begin{tabular}{|c|c|c|c|}
\hline Variable & Number (No.) & \multicolumn{2}{|c|}{ Percentage $(\%)$ * } \\
\hline \multicolumn{4}{|l|}{ Gender } \\
\hline Male & & 49 & 53.3 \\
\hline Female & & 43 & 46.7 \\
\hline \multicolumn{4}{|c|}{ Age (Years) } \\
\hline $0-2$ & & 24 & 26.1 \\
\hline$>2$ & 6 & 39 & 42.4 \\
\hline$>6$ & 12 & 23 & 25 \\
\hline$>12-16$ & & 6 & 6.5 \\
\hline Total & & 92 & 100 \\
\hline
\end{tabular}


Table 2: Number and percentage of 92 orbital lesions among major categories in this study

\begin{tabular}{|l|l|l|}
\hline Lesion & Number (N) & Percent (\%) * \\
\hline Cystic & $(28)$ & -30.4 \\
\hline Dermoid cyst & 24 & 26.1 \\
\hline Mucocele & 3 & 3.3 \\
\hline Colobomatous cyst & 1 & 1.1 \\
\hline Vascular & $(13)$ & -14.1 \\
\hline Capillary hemangioma & 10 & 10.9 \\
\hline Lymphangioma & 3 & 3.3 \\
\hline Lipomatous (Dermolipoma) & $(10)$ & -10.9 \\
\hline Inflammatory & $(9)$ & -9.8 \\
\hline Orbital cellulitis & 6 & 6.5 \\
\hline Idiopathic orbital inflammation & 3 & 3.3 \\
\hline Neurogenic & $(7)$ & $(7.6)$ \\
\hline Optic nerve glioma & 2 & 2.2 \\
\hline Neurofibromatosis type 1 & 5 & 5.4 \\
\hline Lymphoproliferative/leukemic & $(6)$ & -6.5 \\
\hline Lymphoma (Non-lacrimal gland origin) & 1 & 1.1 \\
\hline Acute leukemia & 5 & 5.4 \\
\hline Myogenic (Rhabdomyosarcoma) & $(5)$ & -5.4 \\
\hline Lacrimal gland & $(5)$ & -5.4 \\
\hline Dacryoadenitis & 4 & 4.3 \\
\hline Lymphoma & 1 & -3.1 \\
\hline Secondary (Retinoblastoma) & $(4)$ & -4.3 \\
\hline Metastatic (Neuroblastoma) & & \\
\hline Histiocytic (Eosinophilic granuloma) & $(2)$ & \\
\hline Total & & \\
\hline * Percent's are rounded & & \\
\hline
\end{tabular}

Table 3. Number and percentage of individual orbital tumours in this study

\begin{tabular}{|l|l|l|}
\hline Type & Number (No.) & Percentage (\%) \\
\hline Dermoid cyst & 24 & 26.1 \\
\hline Capillary hemangioma & 10 & 10.9 \\
\hline Dermolipoma & 10 & 10.9 \\
\hline Rhabdomyosarcoma & 5 & 5.4 \\
\hline Retinoblastoma & 4 & 4.3 \\
\hline Neuroblastoma & 3 & 3.3 \\
\hline Plexiform neurofibroma & 3 & 3.3 \\
\hline Optic nerve glioma & 2 & 2.2 \\
\hline Lymphoma & 2 & 2.2 \\
\hline Eosinophilic granuloma & 2 & 2.2 \\
\hline * Percent's are rounded & & \\
\hline
\end{tabular}

Abdallah/Abdellatif/Elhwary/Hassan/Kamel/Saman/Ahmad

Table 4: The main presenting clinical features for each major category of orbital lesions

\begin{tabular}{|c|c|}
\hline Major categories & Presenting clinical manifestations \\
\hline \multirow[t]{3}{*}{ (1) Cystic } & $\begin{array}{l}\text { - A slowly progressive, painless, subcutaneous mass, } \\
\text { attached to }\end{array}$ \\
\hline & $\begin{array}{l}\text { superotemporal or superonasal orbital rim (Superficial } \\
\text { dermoid) }\end{array}$ \\
\hline & - Slowly progressive, painless proptosis (Deep dermoid) \\
\hline \multirow[t]{2}{*}{ (2) Vascular } & $\begin{array}{l}\text { - Strawberry-colored upper eyelid lesions (Capillary } \\
\text { hemangioma). }\end{array}$ \\
\hline & $\begin{array}{l}\text { - Diffuse lid, conjunctival and orbital vascular lesions } \\
\text { (Lymphangioma) }\end{array}$ \\
\hline \multirow[t]{3}{*}{ (3) Myogenic (RMS) } & - Non-axial proptosis with limitation of ocular motility \\
\hline & $\begin{array}{l}\text { - Acute inflammatory signs and symptoms (Orbital } \\
\text { cellulitis-like picture) }\end{array}$ \\
\hline & - Recurrence of orbital tumour \\
\hline \multirow[t]{2}{*}{ (4) Neurogenic } & - Axial Proptosis (ONG) \\
\hline & $\begin{array}{l}\text { - Plexiform NF, café-au-lait spots, ONG, Congenital } \\
\text { glaucoma (NF 1) }\end{array}$ \\
\hline (5) Lacrimal gland & - Non-axial, painful proptosis \\
\hline (6) Lipomatous & $\begin{array}{l}\text { - Anterior conjunctival soft tissue mass at outer canthus } \\
\text { (Dermolipoma) }\end{array}$ \\
\hline $\begin{array}{l}\text { (7) Lymphoid/ } \\
\text { leukemic }\end{array}$ & - Bilateral proptosis, marked pallor, purpuric eruptions \\
\hline \multirow[t]{2}{*}{ (8) Secondary (RB) } & - Recurrent orbital mass (Recurrent orbital RB) \\
\hline & - Orbital cellulitis-like picture (Necrotic intraocular RB) \\
\hline (9) Metastatic & - Unilateral or bilateral proptosis + Eyelid ecchymosis \\
\hline (10) Histiocytic & - Non-axial, painful proptosis + Temporal bulge \\
\hline
\end{tabular}

The diagnosis was clinically-based in 77 cases (83.7\%); and biopsy-proved with histopathologic confirmation in 15 cases $(16.3 \%)$. Benign orbital lesions accounted for 72 cases, constituting $78.3 \%$ of the total orbital lesions; while malignant orbital lesions accounted for 20 cases constituting $21.7 \%$. The most common orbital lesion and the commonest benign lesion in this series was dermoid cyst (24 cases, $26.1 \%$ ), followed by Capillary hemangioma (10 cases, $10.9 \%)$. For the purpose of discussion, the breakdown of the major categories into more specific diagnoses will be shown as follows (in order of frequency): 
Citation: Abdallah AM, Abdellatif MA, Elhwary AM, et al. Pediatric Orbital Tumours in Upper Egypt: A 3-year Retrospective Analysis at a University Hospital. J Clin Ophthalmol 2019;3(1):105-120.

\section{Cystic lesions (Figure 2)}
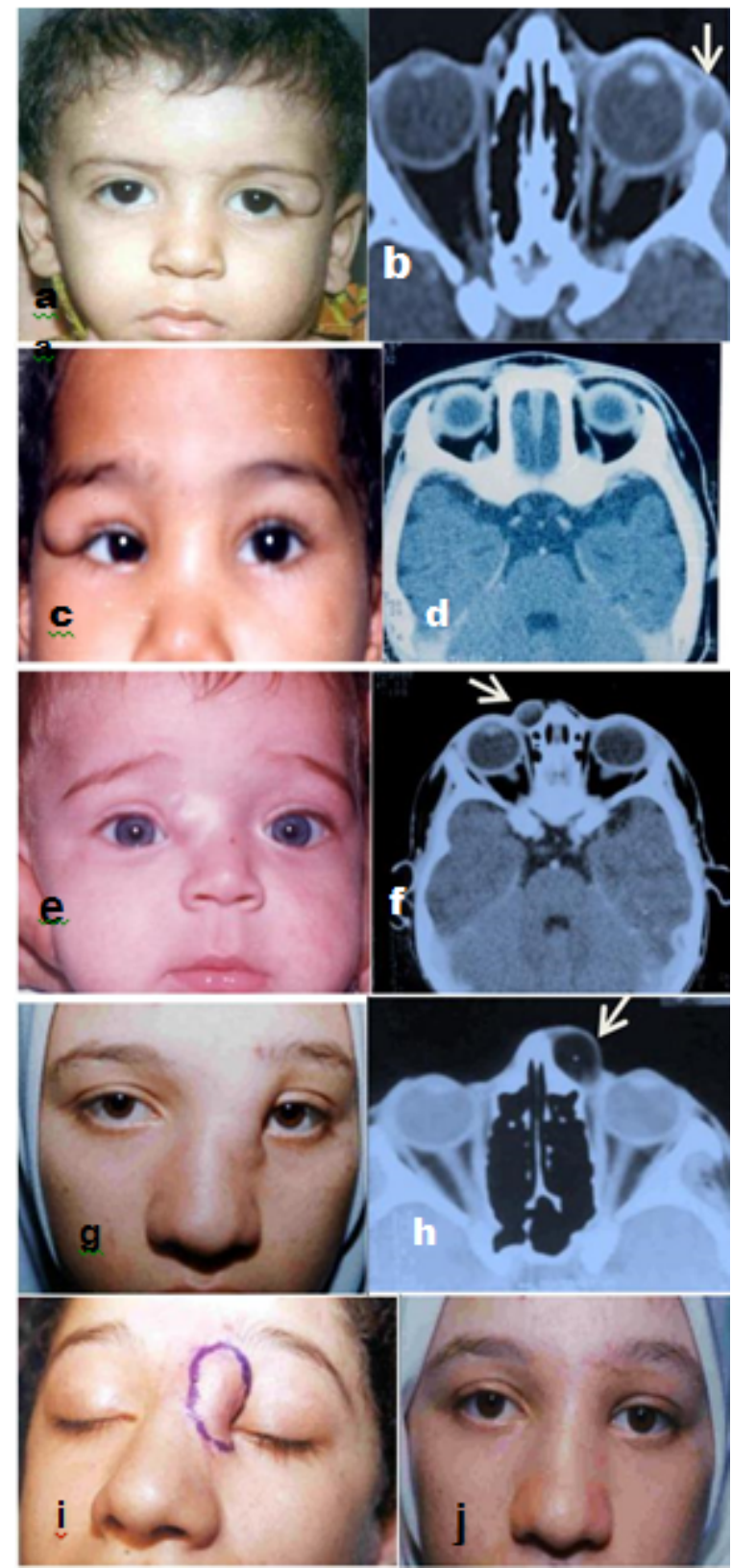

Figure 2: Orbital cystic lesions (Dermoid cyst). (a,c,e,g) Clinical photographs of superficial temporal $(a, c) \&$ nasal $(e, g)$ dermoid cysts. (b,d,f,h) Orbital axial CT scans showing well-defined, encapsulated, radiolucent masses attached to the orbital rim at the superotemporal $(b, d)$ \& superonasal $(f, h)$ orbital quadrants (white arrows). (i,j) Intraoperative \& postoperative photographs of the same patient in (g).

This group included 28 benign cystic lesions (excluding lacrimal gland cysts) constituting $30.4 \%$ of all orbital lesions in this study. Dermoid cyst was the most common benign orbital lesion accounted for 24 cases, constituting $26.1 \%$ of all orbital lesions; of these, 21 were superficially located and attached to the orbital rim either superotemporally Figure 2 a,c) (13 cases), or superonasally Figure $2 \mathrm{e}, \mathrm{g})(8$ cases $)$; and 3 cases were deeply located in the orbital cavity. All superficial dermoids were diagnosed during the first 3 years of life except one 10year-old girl Figure $2 \mathrm{~g}$ ). The 3 deep dermoids were seen at the age of 11, 14 and 15 years. All dermoids were excised through anterior orbitotomy approach, except one which was excised through a lateral orbitotomy approach due to its deep location in the orbital cavity. The other 4 cystic lesions included one colobomatous cyst (microphthalmos with cyst), and 3 orbital mucoceles.

\section{Vascular lesions (Figure 3)}

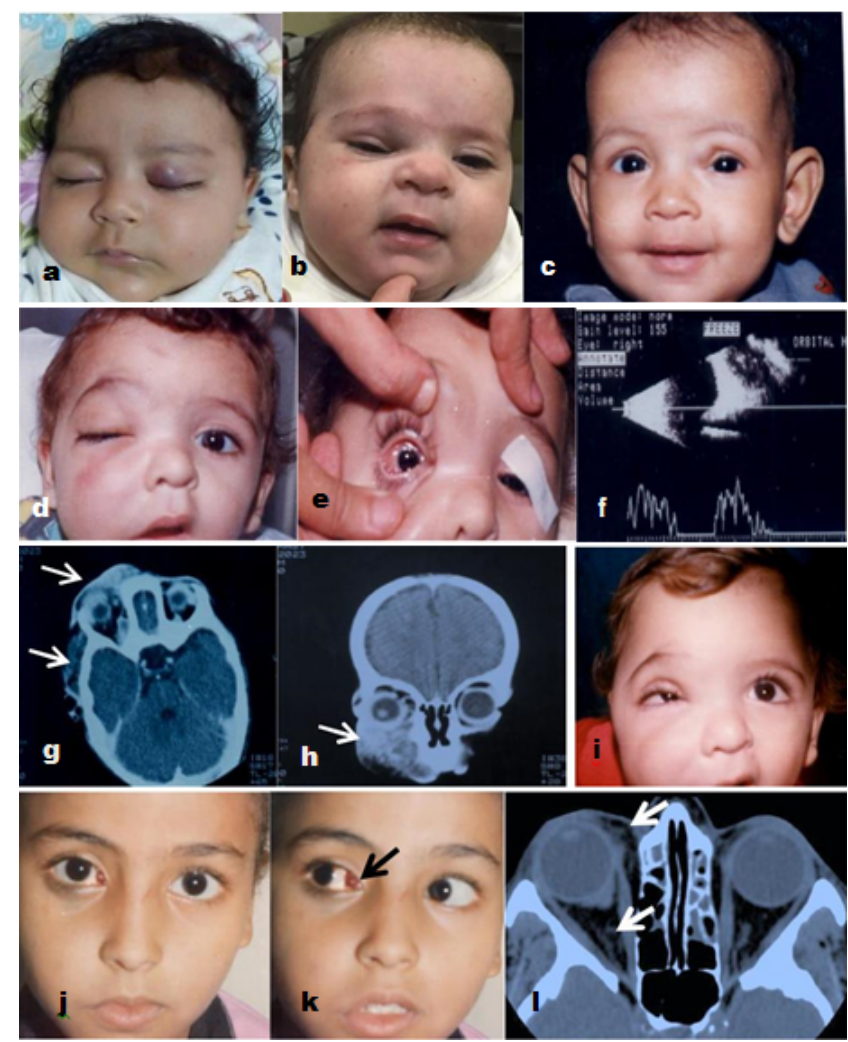

Figure 3: Orbital vascular lesions. ( $a, b, c)$ Capillary hemangiomas of the upper lids in 3 infants. (d - l) Orbital lymphangiomas (d) A clinical photograph of a 2-year-old male child with right severe lid ptosis, proptosis \& hemifacial deformity due to orbital lymphangioma (e) Examination under general anesthesia showing infiltration of the conjunctiva of the right eye by lymphangioma. (f) Orbital ultrasonography of the right eye showing a non-encapsulated intraorbital mass lesion (arrow). ( $g$, h) Axial \& coronal orbital CT scans showing a large ill-defined soft tissue mass involving the right upper lid and extending to the right cheek (arrows). (i) The same infant after surgical debulking of the right upper lid lesion. (j,k) Two clinical photographs of a 9-year-old girl with a right inner canthal vascular lesion (arrow). (l) Orbital axial CT scan of the same patient showing an ill-defined right orbital vascular tissue due to lymphangioma (arrows).

This group included 13 benign vascular lesions constituting $14.1 \%$ of all orbital lesions in this study. Capillary hemangioma was the most common orbital vascular lesion, and the second most common benign orbital lesion (10 cases, $10.9 \%)$. All capillary hemangiomas were seen within the first year of life Figure $3 a, b, c)$. The diagnosis was made clinically in 9 of these cases, while excisional biopsy was performed in one case with atypical presentation to confirm the diagnosis and rule out the possibility of rhabdomyosarcoma. Conservative treatment with periodic observation was 
recommended for 7 cases; intralesional steroid injection was done in 2 cases; and partial surgical debulking was done in one case to prevent occlusion (sensory deprivation) amblyopia. Orbital Iymphangioma was the second most common orbital vascular lesion (3 cases, 3.3\%). Among these cases, a 2-yearold boy presented during an acute hemorrhagic attack with severe proptosis associated with swelling of the upper lid and cheek Figure 3 d,e). His mother reported a history of similar intermittent attacks since birth. A surgical debulking of the upper lid lesion was done to improve the cosmetic appearance and prevent occlusion amblyopia Figure 3 i). A 9-year-old girl with orbital lymphangioma presented with an inner canthal vascular mass Figure j,k), which with orbital CT scan proved to be associated with ill-defined right orbital vascular tissue due to lymphangioma Figure 3). No malignant orbital vascular lesions were encountered in this series.

\section{Lipomatous lesions}

This group included 10 cases of dermolipomas constituting $10.9 \%$ of the all orbital lesions in this study. The age of patients ranged from 4 - 15 years. Regular follow-up was recommended for 7 patients, and 3 lesions were surgically debulked for cosmetic purposes through an anterior transconjunctival approach.

\section{Inflammatory lesions (Figure 4)}

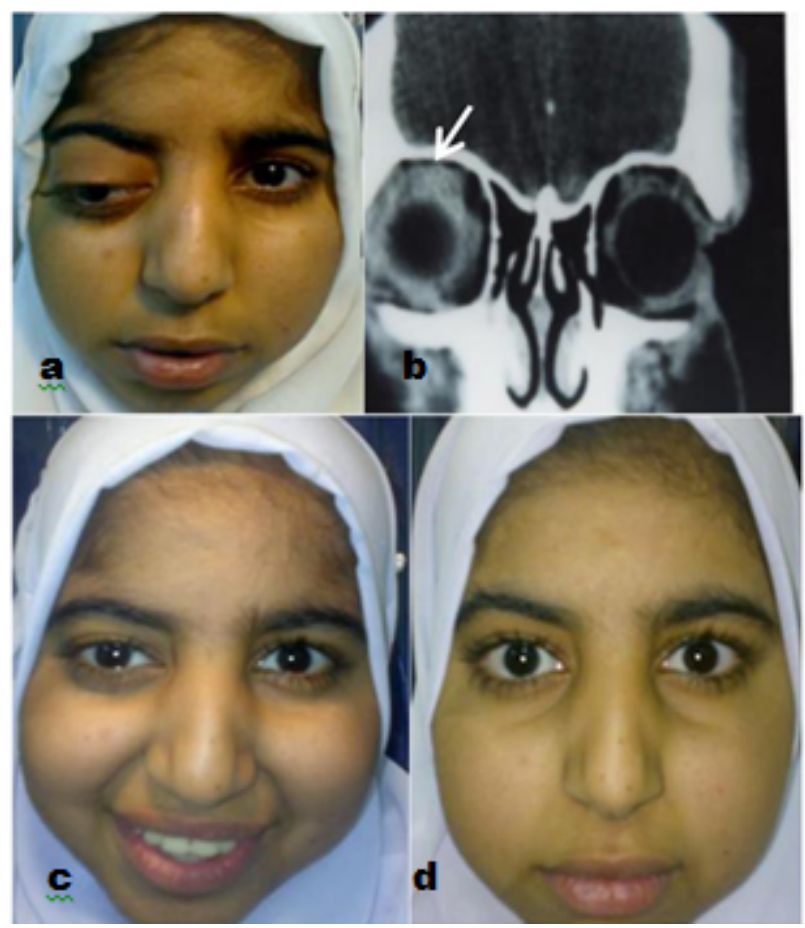

Figure 4: Orbital inflammatory lesions. (a) A clinical photograph of a 12-year-old female child showing right lid edema and non-axial proptosis. (b) A coronal orbital CT scan showing diffuse orbital inflammation (arrow). $(d, e, f)$ Clinical photographs of the same patient one week (c) and 2 weeks (d) after systemic steroid therapy with resolution of inflammation.

This group included 9 cases constituting $9.8 \%$ of all orbital lesions in this study; of these, 6 cases of orbital cellulitis, and 3 cases of idiopathic orbital inflammation (Non-lacrimal gland origin). All patients with orbital cellulitis were related to ethmoidal sinusitis, and responded well to systemic and topical broad-spectrum antibiotic therapy. Patients with idiopathic orbital inflammation presented with unilateral proptosis associated with orbital inflammatory signs and symptoms Figure3). They were treated with systemic steroids with marked improvement and no recurrence till end of the study.

\section{Neurogenic lesions (Figure 5)}

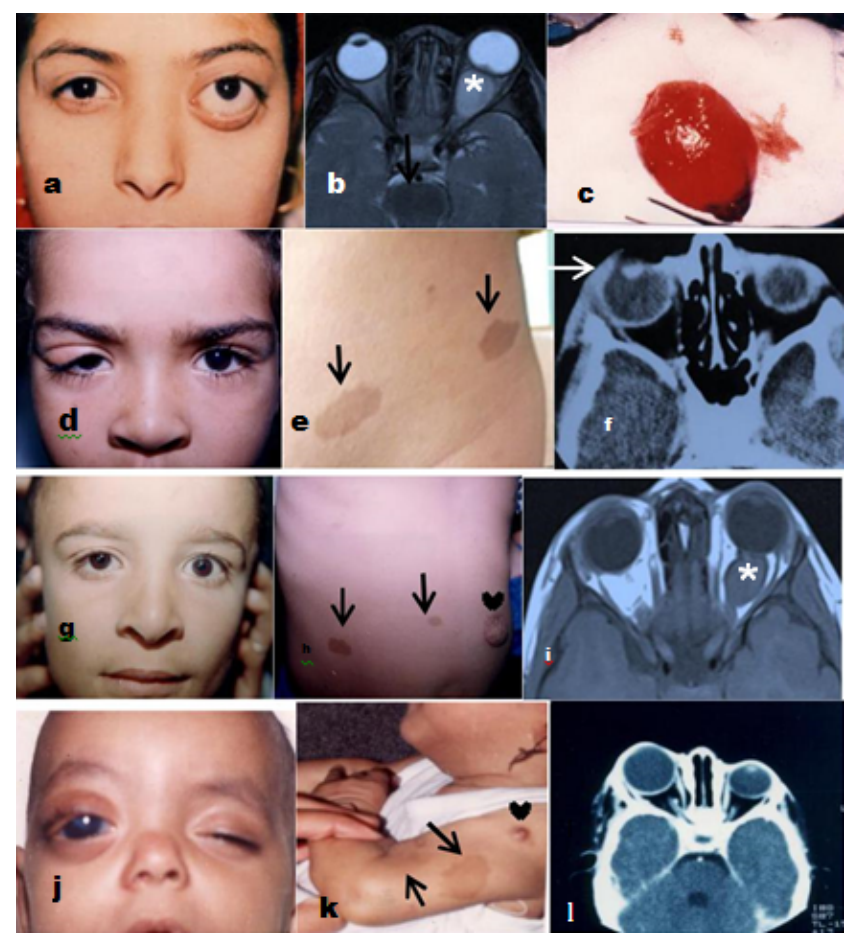

Figure 5: Neurogenic lesions: Optic nerve glioma. (a) A clinical photograph of a 12-year-old female child with right axial proptosis. (b) Axial T2 MRI showing a retrobulbar fusiform orbital mass involving the left optic nerve (*). (c) Intraoperative photograph of the excised optic nerve glioma. Neurofibromatosis 1. (d) Right upper lid plexiform neurofibroma with a characteristic S-shaped deformity (e) Characteristic "Café-au-lait spots" (arrows) (f) Axial orbital CT scan with thickening of temporal part of right upper lid (arrow). (g) A clinical photograph of a 6-year-old male child showing left axial proptosis. (h) The same child with "Café-au-lait spots" (arrows) and neurofibroma (arrowhead). (i) Axial T1 MRI showing a retrobulbar fusiform orbital mass involving the left optic nerve (*). (j) A clinical photograph of one-year-old female infant during examination under general anesthesia showing enlarged right globe with corneal opacity. (k) The same infant with "Café-au-lait spots" (arrows) and neurofibroma (arrowhead). (l) Axial orbital CT scan showing enlarged right globe and orbit.

This group included 7 cases constituting $7.6 \%$ of all orbital lesions; of these, 2 cases with optic nerve glioma (ONG) Figure $5 \mathrm{a}, \mathrm{b}, \mathrm{c}$ ), and 5 cases with neurofibromatosis type 1 (NF 1), which was associated with eyelid plexiform neurofibroma in 3 patients Figure 5 d,e,f), ONG in one patient Figure $5 \mathrm{~g}, \mathrm{~h}, \mathrm{i}$ ), and unilateral congenital glaucoma (Buphthalmos) in one patient Figure $5 \mathrm{j}, \mathrm{k}, \mathrm{l})$. The diagnosis was made clinically in all cases. All NF 1 patients had cutaneous changes in the form of light brownish pigmentary lesions (Café-au-lait spots). Excision of ONG through a lateral orbitotomy approach was 
Citation: Abdallah AM, Abdellatif MA, Elhwary AM, et al. Pediatric Orbital Tumours in Upper Egypt: A 3-year Retrospective Analysis at a University Hospital. J Clin Ophthalmol 2019;3(1):105-120.

done in a 12-year-old girl, who presented with left severe proptosis and optic atrophy Figure 5c). Partial surgical debulking of the eyelid plexiform neurofibroma was done in a 6 -year-old boy to improve the cosmetic appearance, without recurrence of the lesion till the end of the study.

\section{Lymphoproliferative/Leukemic lesions}

This group included 6 cases constituting $6.5 \%$ of all orbital lesions in this study; of these, one case proved histopathologically as orbital lymphoma (Non-lacrimal gland origin), and 5 cases of acute leukemia ( 2 cases with acute lymphoblastic leukemia and 3 cases with acute myelogenous leukemia). The patient with orbital lymphoma had bilateral proptosis associated with hepatosplenomegally; and those with acute leukemia had bilateral proptosis, marked pallor, and purpuric eruptions. All patients in this group were initially presented to the oncology clinic, then, referred to the ophthalmology department for a complete ophthalmologic assessment.

\section{Myogenic lesions (Figure 6)}

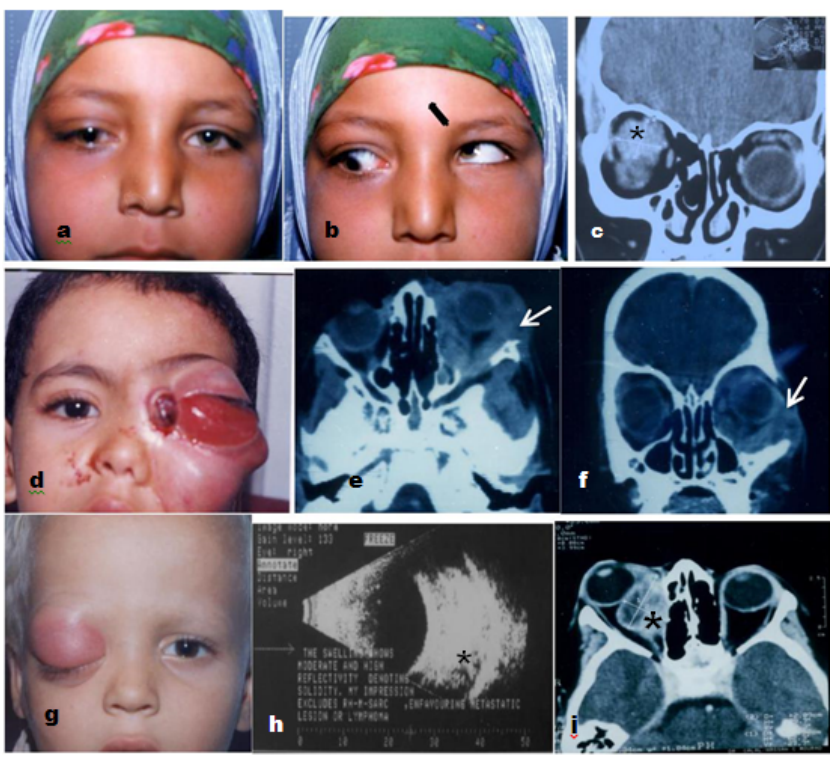

Figure 6: Myogenic lesions (Rhabdomyosarcoma). (a, b) Two clinical photographs of a 10-year-old female child with $R$. non-axial proptosis and limitation of ocular motility in elevation (arrow). (c) Coronal orbital CT scan showing $R$. orbital soft tissue mass (*). (d) A clinical photograph of a 4-year-old male child with left recurrent rhabdomyosarcoma. (e,f) Axial \& coronal orbital CT scans showing extensive enhancing soft tissue mass involving the left orbit, eroding the lateral orbital wall, and extending into the left cheek (arrows). (g) A clinical photograph of a 3-year-old male child with right proptosis associated with edema \& redness of the upper lid. (h) Orbital ultrasonography of the same patient showing a right orbital mass (*). (f) Axial orbital CT scan of the same patient showing a right nasal orbital mass displacing the globe laterally (*)

This group included 5 cases of orbital rhabdomyosarcoma (RMS), constituting 5.4\% of all orbital lesions; of these, 4 with primary (1ry) RMS Figure 6 a), and one with recurrent RMS. Figure $6 \mathrm{~d}$ ). The main presenting clinical manifestations included proptosis (one case), globe displacement with limitation of ocular motility ( 2 cases) Figure 6 a), proptosis, and eyelid swelling and redness "orbital cellulitis-like picture" (one case), Figure 6g), and the patient with extensive recurrent orbital mass. All cases were biopsied before treatment to confirm the diagnosis. Histopathologically, 4 cases were embryonal, and one case was alveolar RMS. Primary RMS cases were treated according to the guidelines and recommendations of IRS with combined chemotherapy and radiotherapy; and recurrent RMS was treated with total exenteration, however, he died 3 months later because of widespread systemic metastases.. Recurrence of the orbital mass occurred in one out of the 4 1ry RMS patients, who was treated with surgical excision of the mass together with postoperative combined chemotherapy and radiotherapy, with no 2 nd recurrence during the follow up period. The final best corrected visual acuity in the 4 patients who maintained their globes till end of the study was $6 / 12$ in one patient, $6 / 24$ in 2 patients, and $1 / 60$ in one patient due to development of complicated cataract.

\section{Lacrimal Gland lesions}

This group included 5 lacrimal gland lesions, constituting 5.4\% of all orbital lesions; of these 4 cases of dacryoadenitis, and one case proved histopathologically as lacrimal gland lymphoma. Among the patients with dacryoadenitis, the inflammation improved markedly with systemic steroid therapy in 2 patients, and appeared to be a variant of idiopathic orbital inflammation.

\section{Secondary lesions (Figure 7)}

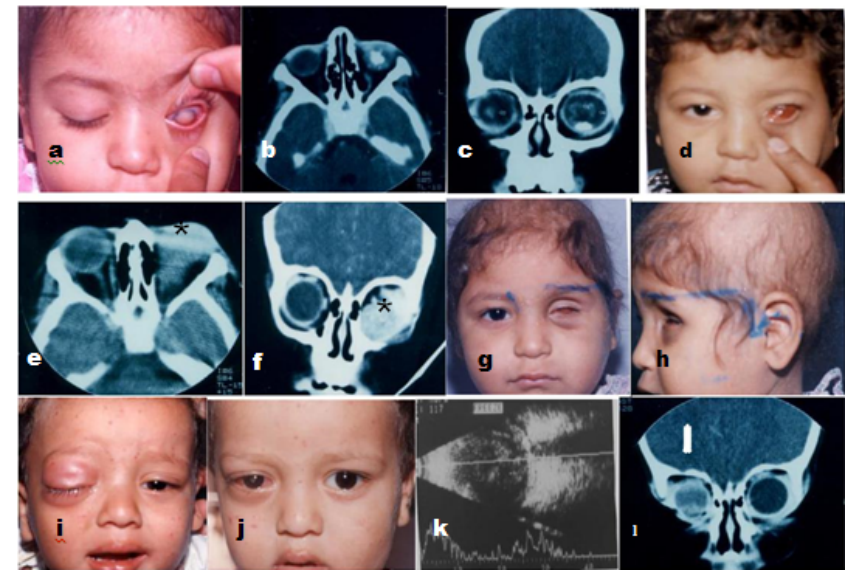

Figure 7: (a) A clinical photograph of a 3-year-old female child with left whitish pupil "leukocoria". (b, c) Axial \& coronal CT scans showing left intraocular retinoblastoma with calcification (d) A clinical photograph of the same child with recurrent orbital mass after enucleation of the left globe. (e, f) Axial \& coronal orbital CT scans showing left orbital mass due to recurrent retinoblastoma $(*)$. $(g, h)$ The same child after combined chemotherapy and external beam radiotherapy with shrinkage in the size of the orbital mass. (i) A clinical photograph of a 3-year-old male child with orbital cellulitis-like picture. (j) A clinical photograph of the same child after treatment of inflammation showing $R$. leukocoria. (k) B-scan ultrasonography showing $R$. intraocular lesion. (l) Orbital CT scan of the same child showing $R$. intraocular retinoblastoma with calcification (arrow). 
This group included 4 cases of retinoblastoma (RB), constituting $4.3 \%$ of all orbital lesions; of these, 2 patients with recurrent orbital RB after enucleation Figure $7 \mathrm{a}-\mathrm{h}$ ), one case with advanced orbital RB due to extraocular spread, and one case presented with orbital cellulitis-like picture because of necrotic intraocular RB Figure 7 i-1), for whom, enucleation of the right eye was done. No other secondary orbital tumours originating from the neighboring structures (eyelid, conjunctiva and paranasal sinuses) were seen in this study. Subtotal exenteration was done for 2 patients with recurrent orbital RB, total exenteration for advanced extraocular RB, and enucleation for necrotic intraocular $\mathrm{RB}$, in addition to postoperative combined chemotherapy and radiotherapy Figure $7 \mathrm{~g}, \mathrm{~h})$.

\section{Metastatic lesions (Figure 8)}

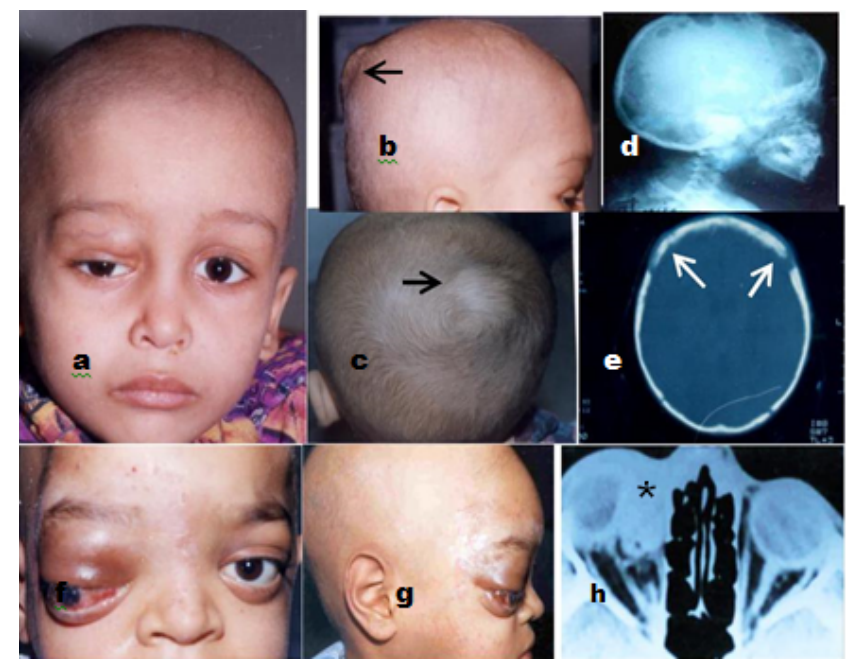

Figure 8: Orbital metastatic neuroblastoma. (a) A clinical photograph of a 3-year-old male child showing $R$. upper lid ptosis and ecchymosis, associated with downward proptosis. (b, c) Clinical photographs showing skull swellings (arrows). (d,e) Skull views showing skull osteolytic lesions (arrows). (f) A clinical photograph of a 3-year-old male child showing R. upper lid ecchymosis, associated with severe downward and outward proptosis before starting chemotherapy. (g) The same patient after 1st cycle of chemotherapy with decrease in the degree of proptosis. (h) Axial orbital CT scan of the same patient showing an orbital mass (*).

This group included 3 cases of metastatic neuroblastoma, constituting $3.3 \%$ of all orbital lesions. All patients presented with proptosis associated with eyelid ecchymosis Figure 8 a,f). The primary tumour located in the suprarenal (adrenal) gland in the 3 patients. Orbital mass biopsy was done for all cases, and proved histopathologically as neuroblastoma. All patients were treated with chemotherapy. One patient died during the study despite partial remission and continuation of chemotherapy due to development of brain metastases and bone marrow depression.

\section{Histiocytic lesions (Figure 9)}

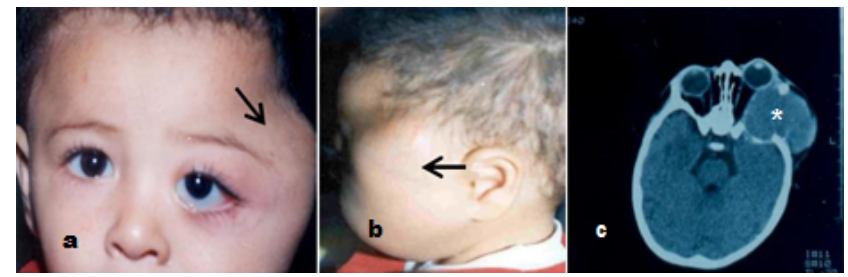

Figure 9: Histiocytic lesions (Eosinophilic granuloma). (a, b) Two clinical photographs of a 2-year-old male child showing left downward proptosis, associated with temporal bulge (arrows). (c) Axial orbital CT scan of the same child showing a left large lobulated orbital mass, eroding the left lateral orbital wall and extending intracranially $(*)$

This group included 2 cases of eosinophilic granuloma, constituting $2.2 \%$ of the total orbital lesions. Patients presented with painful tender temporal swellings associated with proptosis Figure 9). The tumour was excised through a lateral orbitotomy approach and proved histopathologically as eosinophic granuloma. Postoperative orbital radiotherapy was done.

\section{Discussion}

The reported incidence of orbital tumours varies widely from series to series [14-18]. A review of the literature revealed marked differences between biopsy-proven studies $[15,16]$, and clinically-based studies [17,18], [Table 5]. Biopsy-proven studies are sometimes important for accurate diagnostic aspects, however, such series may reveal lower incidence for certain orbital lesions that are often diagnosed clinically without the need for a biopsy such as dermoid cyst, capillary hemangioma, optic nerve glioma, fibrous dysplasia and certain others [17]. In our study, biopsy was performed in selected cases when indicated to confirm the diagnosis. When the classic clinical and radiographic features for an orbital lesion pointed to a straightforward diagnosis, especially when benign in nature, a presumptive diagnosis was clinically based without a biopsy. This was evident for patients with dermoid cysts, dermolipomas most capillary hemangiomas (except one to rule out the possibility of malignancy), optic nerve gliomas, and most orbital inflammatory lesions (except one that proved after biopsy to be a RMS). On the other hand, all RMS cases were biopsied before treatment to confirm the diagnosis. The review of literature also revealed a marked differences between studies stressed on specific diagnoses [2-7,20,21], or malignant orbital tumours only $[22,23]$, and those that evaluate orbital tumours in general $[1,14,17,18]$. When the patient age is considered in the survey, the incidence varies tremendously in children [10,19,24-28], versus adults [29]. Some Pediatric orbital tumours such as optic nerve glioma and capillary hemangioma are not usually encountered in adults in clinical practice $[1,2,20]$. Our study was conducted on Pediatric patients only. 
Citation: Abdallah AM, Abdellatif MA, Elhwary AM, et al. Pediatric Orbital Tumours in Upper Egypt: A 3-year Retrospective Analysis at a University Hospital. J Clin Ophthalmol 2019;3(1):105-120.

Table 5: A Comparison between a histologically-based and clinicallybased series.

\begin{tabular}{|l|l|l|}
\hline Lesion & Shields $^{*}$ & Bullock \# \\
\hline & $\%$ & $\%$ \\
\hline Cystic & 52 & 41.8 \\
\hline Vasculogenic & 6.8 & 16.3 \\
\hline Inflammatory & 16.4 & 3.5 \\
\hline Adipose-containing & 6.8 & 7.8 \\
\hline Rhabdomyosarcoma & 4 & 2.1 \\
\hline Secondary/metastatic & 2.4 & 2.1 \\
\hline Lacrimal gland (fossa) & 3.6 & 2.8 \\
\hline Lymphoid/leukemias & 2.4 & 3.5 \\
\hline Optic nerve/meningeal & 2.4 & 5 \\
\hline Osseousand cartilagenous & 1.2 & 5 \\
\hline Histiocytic & 0.4 & 2.1 \\
\hline Melanocytic & 0 & 0 \\
\hline Miscellaneous & 0 & 1.4 \\
\hline Total No. of Lesions & 250 & 141 \\
\hline * Histologicahy-based series [19] & & \\
\hline \# Clinically-based series [17] & & \\
\hline
\end{tabular}

The geographical location of the survey, also, influences the incidence of orbital tumours. Most Pediatric orbital tumour series reported from the United States, Western Europe and developed countries have revealed that benign cystic lesions were the most common orbital lesions [16-19,24,25,30], [Table 6]. On the other hand, most series reported from the Middle East and developing countries have revealed that orbital retinoblastoma was the most common [31-37], [Table 7].

Table 6: Number and percent of benign cystic lesions in 6 series of Pediatric orbital tumours

\begin{tabular}{|l|l|l|l|}
\hline Series & $\begin{array}{l}\text { Total No. of } \\
\text { lesions }\end{array}$ & $\begin{array}{l}\text { No. of benign cystic } \\
\text { lesions }\end{array}$ & $\%{ }^{*}$ \\
\hline Shields [19] & 250 & 130 & 52 \\
\hline Yousefi [25] & 62 & 31 & 50 \\
\hline Eldrup-jorgensen [41] & 80 & 38 & 48 \\
\hline Bullock [17] & 141 & 59 & 42 \\
\hline Illif and green [42] & 174 & 60 & 35 \\
\hline Kodsi [27] & 340 & 79 & 23 \\
\hline *Percents are rounded & & \\
\hline
\end{tabular}

Table 7. A Comparison between our series and others in different countries.

\begin{tabular}{|l|l|l|l|l|l|}
\hline Lesion & Egypt & KSA $^{*}$ & Turkey & Pakistan\# & USA\#\# \\
\hline Cystic & 30.4 & 18.2 & 21.8 & 7 & 52 \\
\hline Vascular & 14.1 & 22.3 & 5.6 & 6.3 & 6.8 \\
\hline Myogenic (RMS) & 5.4 & 3.4 & 17.6 & 1.1 & 4 \\
\hline
\end{tabular}

\begin{tabular}{|l|l|l|l|l|l|}
\hline Neurogenic & 7.6 & 6.8 & 6.1 & 5.5 & 2.4 \\
\hline Lymphoid/leukemic & 6.5 & 1.4 & 4.8 & 2.1 & 2.4 \\
\hline Osseous/cartilaginous & 0 & 0.7 & 2.1 & 4.6 & 1.2 \\
\hline Lipomatous & 10.9 & 0.7 & 0.8 & 1.8 & 6.8 \\
\hline Lacrimal Gland & 5.4 & 2.7 & 0.3 & 0 & 3.6 \\
\hline Secondary (RB) & 4.3 & 33 & 32.8 & 65.5 & 1.2 \\
\hline Metastatic & 3.3 & 4.1 & 1.3 & 1.4 & 1.2 \\
\hline Histiocytic & 2.2 & 0.7 & 0 & 0 & 0.4 \\
\hline Inflammatory & 9.8 & 2.7 & 5.6 & 3.5 & 16.4 \\
\hline Miscellaneous & 0 & 0.7 & 0.5 & 1.4 & 0 \\
\hline Total No. of lesions & 92 & 148 & 376 & 284 & 250 \\
\hline References No. [34,36,28,19] & & & \\
\hline
\end{tabular}

The medical specialty of the author also influences the incidence of the reported orbital tumours [19,35,38-40]. McCarty and Brown [38], in their study of primary intraorbital childhood tumours approached transcranially, reported a frequency of $50 \%$ for optic nerve gliomas, which was not surprising since neurosurgeons are primarily concerned with this type of tumour in childhood. Therefore, it should be stressed that the results of our study may reflect the incidence of Pediatric orbital tumours expected in an ophthalmic clinic but not of other specialties.

In our study, benign orbital lesions accounted for 72 cases (78.3\%); while malignant orbital lesions accounted for 20 cases $(21.7 \%)$ of total orbital lesions. The lower incidence of malignant versus benign orbital tumours in our study may be explained by the presence of a specialized cancer institute in Sohag City (Sohag Cancer Institute), to which many patients with malignant ocular and orbital tumours may be referred by other physicians for further evaluation and proper treatment; while most benign orbital lesions such as dermoid cyst, capillary hemangioma and others are usually referred to the ophthalmology department in our hospital.

Dermoid cyst was the most common orbital lesion in our series (24 cases, 26.1\%). This was, also, reported by Shields [19], and others $[25,27,41,42]$. A dermoid cyst is an epithelium-lined structure with dermal appendages in its wall and keratin and hair in its lumen. It is believed to develop from rests of surface epithelium which become entrapped within the sites of fetal fissures. This explains their tendency to occur along the zygomaticofrontal and nasofrontal sutures. Although being considered as a congenital lesion, it may not be evident at birth. It generally becomes apparent during the first decade of life. Patients with superficial dermoids in our study were diagnosed during the first 3 years of life, except one 10-yearold girl; and they characteristically presented with a slowly progressive, painless, subcutaneous mass, attached either to the superotemporal or superonasal orbital rim. While the 3 deep dermoids were seen in patients aged 11,14 and 15 years; who presented with a slowly progressive, painless proptosis. The CT features of dermoid cyst was very characteristic, in which it typically appeared as a well-defined, thin-walled structure with 
a nonenhancing lumen. Based on the clinical and radiologic features, all dermoid cysts in this series were diagnosed clinically without a biopsy $[43,44]$. The goal of treatment of dermoid cysts in our study was to do complete surgical excision of the cyst, with gentle dissection from its attachments to the bony sutural lines, and without rupture of the cyst wall to avoid a severe postoperative inflammatory reaction. However, cyst wall rupture accidentally occurred in 2 superficial dermoids, and was treated with intraoperative copious irrigation of the surgical field with removal of the cyst remnants. All dermoids were excised through anterior orbitotomy approach, except one deep dermoid which was excised through lateral orbitotomy approach; with good postoperative anatomical, functional and cosmetic results in all cases.

Capillary hemangioma was the second most common orbital lesion, and the most common vascular orbital lesion, in our study. It is composed of lobular sheets of endothelial cells that surround small, capillary-like vascular spaces. It is frequently located in the eyelid. However, in some instances there may be anterior orbital involvement as well as the lid lesion [2]. It appears during the first few weeks after birth and enlarges over the following 6 to 12 months. Most capillary hemangiomas shrink by the age of 5 years. It typically increases in size during crying or straining, but is not associated with either pulsation or bruit. The most common sites of involvement are the medial upper eyelid and superior nasal quadrant of the orbit. Superficial types present as strawberry-colored lesions, while deeply located lesions give the skin a bluish discoloration [45]. An orbital CT scan shows it as homogeneous, poorly delineated lesions without bone destruction, which may enhance with contrast [46]. The diagnosis of capillary hemangioma in our study was clinicallybased depending on the typical clinical and radiologic features, except in one case with atypical presentation, in which an excisional biopsy was performed to confirm the diagnosis and rule out the possibility of malignancy. A number of therapeutic modalities have been advocated for treatment of capillary hemangiomas with orbital involvement. The natural tendency of these tumours to regress spontaneously was kept in mind, and the type of treatment selected was generally as conservative as possible and indicated if there was a visual obstruction with a risk of sensory deprivation amblyopia, or associated cosmetic problems [47]. The treatment regimen for capillary hemangiomas in our study included the following: children with small capillary hemangiomas were managed by periodic examination for tumour regression. For large hemangioms causing visual obstruction, intra-lesional corticosteroids injection (Triamcinolone $40 \mathrm{mg} / \mathrm{ml}$ and Betamethasone $6 \mathrm{mg} / \mathrm{ml}$ ) was done to enhance some shrinkage of the lesion. For lesions not responding to steroid injection, partial surgical excision (debulking) was attempted. Conservative treatment with periodic observation was recommended for 7 cases; intralesional steroid injection in 2 cases; and partial surgical debulking in one case. Amblyopia therapy was employed as an adjunctive measure along with the other therapeutic methods.
Orbital lymphangioma was the second most common benign vascular orbital lesion in children in our study. It is a benign, slowly progressive vascular hamartoma of the orbit that is probably congenital but may not become clinically apparent for months or years after birth. The great majority of lymphangiomas become clinically manifest during the first decade of life. In contrast to orbital capillary hemangiomas, lymphangiomas show continued progression and do not regress $[47,48]$. The affected child frequently has conjunctival involvement characterized by a multiloculated cystic mass of the bulbar conjunctiva, which may periodically fill with blood. Bleeding into the vascular spaces of a Iymphangioma can produce a large dark mass known as a "chocolate cyst [49]. Involvement of bulbar conjunctiva with lymphangioma was seen in a 2-year-old child who presented with right proptosis associated with swelling of the upper lid and cheek Figure $2 \mathrm{~d}$, e). Proptosis is usually exacerbated in the presence of an upper respiratory infection with lymphangioma, presumably due to proliferation of lymphoid elements in the connective tissue trabeculae of the tumour [50]. This was seen in this patient. Similar recurrent attacks since birth were reported by his mother. On CT and MRI, orbital lymphangiomas appear as a poorly circumscribed, heterogeneous mass with areas of fluid and blood [51]. Treatment of orbital Iymphangiomas has been controversial. Complete excision is usually not possible due to the diffuse, non-encapsulated growth pattern that allows these tumours to interdigitate with normal orbital structures. Some authors [47,48,52], have recommended repeated subtotal excisions as the most effective method of controlling proptosis, limiting complications, and achieving cosmetic improvement. Conservative management with bed rest, cold compresses, and restricted activity, rather than surgical intervention, was recommended by others [53]. In our study, partial surgical debulking of the upper lid lesion was done in one patient to improve the cosmetic appearance and prevent occlusion amblyopia Figure 2 i); and the other 2 patients were managed conservatively Rhabdomyosarcoma was the most common primary malignant orbital tumour, accounted for 5 cases, constituting $5.4 \%$ of all orbital tumours. The incidence of orbital RMS varies from series to series. In Shield's survey, it accounted for only $1 \%$ of biopsies in all ages [16], and for $4 \%$ of all biopsies in children [19].However, the frequency of RMS among orbital tumours may be higher than indicated in those studies, since the authors included only the cases of RMS in which the biopsy was done at one institution (Wills Eye Hospital); and a number of additional patients, not included in those figures, had had a biopsy elsewhere and were then referred to the oncology service at Wills Eye Hospital for further evaluation and therapeutic recommendations. The clinical differential diagnosis of RMS includes most causes of acute proptosis in childhood. The important lesions to be considered include orbital cellulitis, lymphangioma, idiopathic orbital inflammation, dermoid cyst, capillary hemangioma, eosinophilic granuloma, metastatic neuroblastoma, lymphoma and leukemia. Orbital imaging studies have an important role in the differentiation between these conditions [40, 54]. Therefore, once a RMS is suspected in a child who presents with a recent onset of a rapidly progressive proptosis, urgent biopsy is highly recommended [4]. RMS may resemble other 
non-myogenic sarcomas. Alveolar RMS often harbors a typical translocation, but embryonal RMS lacks any specific rearrangement. So, histopathology is not always sufficient for an unequivocal diagnosis, necessitating ancillary studies, including immunohistochemistry. The most useful immunohistochemical markers for diagnosis include desmin and myogenin $[55,56]$, which were positive in all RMS cases in our study. The survival rate in children with RMS has been changed drastically over the years from $30 \%$ in the 1960 's to $90 \%$ presently, with the efforts of Intergroup Rhabdomyosarcoma Study (IRS), and with the advent of new diagnostic and therapeutic modalities. Current recommendations for the treatment of orbital RMS include combination of chemotherapy and radiotherapy, based on a staging system devised by IRS. Prognosis depends on favorable anatomic location of tumour, early stages of the disease, younger age and favorable tumour morphology [57, 58]. In our study, there were 4 patients with 1ry RMS and one patient presented with advanced recurrent RMS who treated with total exenteration. For 1ry RMS, biopsy was done before treatment to confirm the diagnosis, then they were treated according to the guidelines and recommendations of IRS with combined chemotherapy and radiotherapy. All patients with 1ry RMS, had a good initial response to treatment, however, recurrence of the orbital mass occurred in one patient who was treated with excision of the mass followed by combined chemotherapy and radiotherapy, with no further recurrence. The other 3 patients had no recurrence of the orbital tumour till the end of the follow-up period of the study. The final best corrected visual acuity in the 4 patients who maintained their globes till end of the study was $6 / 12$ in one patient, $6 / 24$ in 2 patients, and $1 / 60$ in one patient due to development of complicated cataract.

Optic nerve glioma (ONG), is a primary tumour of the glial cells of the optic nerve. It is one of the most common neurogenic orbital tumours of childhood [59]. The incidence of optic nerve glioma varies with the type of the survey. In Shield's survey, it accounted for only $0.6 \%$ of biopsies in all ages [16], and for $2 \%$ of all biopsies in children [19]. However, the incidence of ONG is probably higher than that indicated by these biopsy-proved studies, since most patients with ONG are evaluated clinically and are not subjected to a biopsy. ONG usually becomes clinically apparent during the first decade of life. In our study, there were 3 patients with ONG ( 2 males and a female), aged 5, 7 and 12 years, constituting $3.3 \%$ of all orbital lesions; one of them (7-year-old male) had NF 1 . The symptoms and signs of orbital ONG are characteristic and depend largely on the location of the tumour in the optic nerve. The classic clinical features include painless, progressive visual loss associated with axial proptosis, which in most cases is unilateral, but bilateral involvement may occur, particularly in patients with NF 1 . The visual loss is often so slow and insidious that the affected child may be unaware of it. However, if ONG originates in the intracanalicular portion of the optic nerve, severe visual impairment may occur before proptosis. If the tumour involves the immediate retrobulbar portion of the optic nerve, fundus examination initially reveals a swollen hyperemic optic disc. [59]. Helpful ancillary studies include CT scan and MRI.. With CT, the intraconal tumour has a characteristic smooth fusiform appearance. MRI is usually indicated to demonstrate tumour extension through the optic foramen into the intracranial portion of the optic nerve. $[37,40]$. In our study, the 3 patients presented with unilateral axial proptosis associated with diminution of vision, and in one of them, the ONG was associated with NF 1. The diagnosis was made on clinical basis with the aid of CT and MRI, without the need for a biopsy in all patients. Treatment of ONG in children is controversial and complex. The decision to initiate treatment and outcomes depend upon several factors including patient's age, tumour location and size, and visual symptoms [60-61]. Some authors have proposed that it is a benign hamartoma with little potential for growth and invasion and that do not metastasize and may even spontaneously regress [62]. They recommended eye examination every 3 months for the first year, gradually increasing the interval if visual function remains stable. Surgical treatment was only indicated for unsightly proptosis, or when there was evidence of progressive disease, indicated by a combination of functional deterioration of visual function and tumour enlargement on CT and/or MRI imaging [63,64]. Others believe that it is an aggressive neoplasm and recommend as complete total excision as is feasible [64,65], with or without radiation therapy, or radiation therapy only $[66,67]$. In addition, gliomas confined to the optic nerve should be distinguished from those involving chiasm with or without posterior extension. The role of chemotherapy in treatment of optic nerve and chiasmal gliomas was also studied by many authors $[68,69]$. In our study, conservative regular follow-up every 3 months with serial neuro-imaging and ophthalmic examinations was recommended for 2 patients with nonprogressive ONG; and excision of the tumour through a lateral orbitotomy approach was done in a 12-year-old girl, who presented with left severe proptosis and optic atrophy.

An important clinical aspect of the orbital $\mathrm{ONG}$ is its relationship to NF 1 (Von- Recklinghausen's disease) [70]. Although estimates vary considerably, most series with good available clinical data have reported a 40 to $50 \%$ incidence of NF 1 in patients with orbital ONG $[71,72]$. In as many as $95 \%$, of patients, the diagnosis is made on the basis of clinical manifestations. Diagnosis requires the presence of 2 or more major criteria including: 6 or more café-au- lait spots, axillary or inguinal freckling, 2 or more cutaneous neurofibromas, one plexiform neurofibroma $(\mathrm{PN})$, characteristic bony lesions (pseudarthrosis, sphenoid wing hypoplasia), an optic glioma, 2 or more iris (Lisch) nodules, or a first-degree relative with NF1 $[73,74]$. Congenital glaucoma was also reported with NF1 [75], which was seen in one patient with NF1 in our study Figure 4 $\mathrm{j}-1)$. The plexiform NF is considered pathognomonic of NF 1 . In the early stages, it presents with ptosis and thickening of the upper eyelid (S-shaped deformity), Figure 4d). Then, the tumour infiltrates all orbital tissues, making dissection difficult, if not impossible. The management of orbital PN presents a complex problem. The diffuse infiltrating nature of this tumour usually negates the possibility of complete surgical removal. In many instances it seems most prudent to refrain from surgical intervention as long as possible because the 
results of surgery may be more cosmetically disfiguring than the disease process itself. Surgical intervention may ultimately be necessary because of bothersome symptoms, threatened vision, or an unacceptable cosmetic appearance. In such instances the surgeon must often resort to partial excision or debulking procedures to alleviate the problem [73]. Five cases with NF 1 were encountered in our study; of them, 3 cases were associated with eyelid plexiform neurofibroma, one with $\mathrm{ONG}$, and one with right congenital glaucoma (Buphthalmos). The diagnosis was made clinically in all cases. All NF 1 patients had characteristic cutaneous pigmentary changes (Café-au-lait spots). Regarding treatment of NF1 in our study, partial surgical debulking of the eyelid PN was done in one patient to improve the cosmetic appearance and prevent occlusion amblyopia with no recurrence till end of the study; periodic observation was recommended for the other 2 cases with small lid lesions; combined trabeculotomytrabeculectomy with mitomycin $\mathrm{C}$ was done for the patient with buphthalmos; and regular follow up was recommended for the patient with unprogressive ONG.

Retinoblastoma was the only secondary orbital tumour type in this study, accounted for 4 cases, constituting $4.3 \%$ of all orbital tumours. The incidence of extraocular (orbital) retinoblastoma in our study was lower than that reported in previous studies in Egypt. This may be explained by the advent of many recent diagnostic and therapeutic measures over the previous 2 decades, so that, the intraocular RB are nowadays diagnosed at earlier stage and consequently properly treated, with decreasing frequency of orbital extension [76]. Atypical presentation of intraocular RB may occur, with orbital cellulitis-like picture [77,78], which was seen in one of RB cases in our study Figure 6 i-1). A dilated fundus examination under general anesthesia should be done for all children with orbital cellulitis associated with delayed response to the usual systemic antibiotic treatment to rule out a RB. For treatment, subtotal exenteration was done for 2 patients with recurrent orbital RB, total exenteration for advanced extraocular RB, and enucleation for necrotic intraocular $\mathrm{RB}$, in addition to postoperative combined chemotherapy and radiotherapy.

Idiopathic orbital inflammation (misnamed orbital pseudo tumour) in children can be a bilateral disease with acute onset of pain, redness, eyelid edema and proptosis. On imaging studies including orbital CT scan, there may be extraocular muscle enlargement, enlarged lacrimal gland, or thickened sclera, suggestive of myositis, dacryoadenitis and scleritis respectively. In contrast to idiopathic orbital inflammation in adults, children may present with fever, leukocytosis and elevated erythrocyte sedimentation rate (ESR). Systemic steroid use results in dramatic improvement within 24 to 48 hours. Children with multiple recurrences of orbital idiopathic inflammation require biopsy to rule out malignant orbital tumours in children such as RMS [6,7]. In our study, there were 3 patients of idiopathic orbital inflammation (Nonlacrimal gland origin), who responded well with systemic steroid without recurrence of inflammation till the end of the follow-up period of the study. It should be stressed that many malignant orbital tumours may atypically presented with orbital inflammatory symptoms and signs. A careful clinical history, examination, and appropriate imaging studies including orbital CT scan should be done to confirm the diagnosis especially in suspicious cases. Also, a biopsy should be considered for any suspicious benign inflammatory orbital lesion in which a final diagnosis could not be confirmed except after histopathological examination [77,78]. In our study, 2 patients were initially misdiagnosed as primary orbital cellulitis and referred to our department due to delayed response to the usual treatment, for further evaluation and therapeutic options. After full investigation, they proved to be RMS and RB cases.

In conclusion, a variety of benign and malignant Pediatric orbital tumours may be seen in clinical practice. The incidence of any particular orbital tumour depends mainly on the type of study (clinical versus histopathologic), medical specialty of the author, and geographical location of the survey Management of these tumours requires a multidisciplinary approach with a good cooperation between Pediatric ophthalmologist, ophthalmic oncologist, radiologist, chemotherapist, and sometimes the neurosurgeon and oculoplastic surgeon . Every effort should be made to educate the primary care physicians and Pediatricians in Egypt about various ocular and orbital tumours in children, and consequently, facilitate early referral of suspicious cases for more evaluation and treatment. Early diagnosis and prompt treatment provide good cosmetic and functional results and prevent visual loss in the majority of those children.

\section{References}

1. Castillo BV Jr, Kaufman L. Pediatric tumors of the eye and orbit. Pediatr Clin North Am. 2003;50(1):149-72.

2. Haik BG, Jakobiec FA, Ellsworth RM, et al. Capillary hemangioma of the lids and orbit: an analysis of the clinical features and therapeutic results in 101 cases. Ophthalmology. 1979;86(5):760-92.

3. Bonavolonta G, Tranfa F, deConcil iis C. et al. Dermoid cysts: 16 year survey. Ophthalm Plast Reconstr Surg. 1995; 11:187-92.

4. Shields JA, Shields CL. Rhabdomyosarcoma: review for the ophthalmologist. Surv Ophthalmol. 2003;48:39-57.

5. Wright JE, Rose GE, Garner A. Primary malignant neoplasm of the lacrimal gland. $\mathrm{Br} \mathrm{J}$ Ophthalmol. 1992;76:401-7.

6. Cahill KV. Pediatric orbital inflammatory disorders. In: Katowitz JA, ed. Pediatric Oculoplastic surgery. New York: Springer. 1999; 421-33.

7. Yan $\mathrm{J}, \mathrm{Wu} \mathrm{Z}, \mathrm{Li} \mathrm{Y}$. The differentiation of idiopathic inflammatory pseudotumor from lymphoid tumors of orbit: analysis of 319 cases. Orbit. 2004;23(4):245-54.

8. Shields JA, Shields CL, Brotman HK, et al. Cancer metastatic to the orbit: the 2000 Robert M. Curts Lecture. Ophthal Plast Reconstr Surg. 2001;17:346-54.

9. Char DH, Miller T, Kroll S. Orbital metastases: diagnosis and course. Br J Ophthalmol. 1997; 81(5):386-90.

10. Sindhu K, Downie J, Ghabrial R, et al. Aetiology of childhood proptosis. J Pediatric Child Health. 1998;34:374-6. 
11. Wright JE (1981): Causes of orbital disease in 1,041 patients at Moorfields Eye Hospital. In: Krohel GB, Stewart WB, Chavis RM (eds). Orbital Disease. A Practical Approach Grune \& Stratton, New York.

12. Leone CR, Grove AS, LIoyd WC, et al (1992). Clinical investigation and presurgical evaluation of the orbital surgery patient. In: Atlas of Orbital Surgery, W.B. Saunders Company, Philadelphia: Pp. 7-15.

13. Harsh Kandpal, sushma Vashisht, Raju Sharma, et al. Imaging spectrum of pediatric orbital pathology: a pictorial review. Indian J Ophthalmol. 2006;54(4):227-36.

14. Kennedy RE. An evaluation of 820 orbital cases. Trans Am Ophthalmol Soc.1984;82:134-57.

15. Gunalp I, Gunduz K. Biopsy-proven orbital lesions in Turkey: a survey of 1092 cases over 30 years. Orbit. 1994;13:67-79.

16. Shields JA, Bakewell B, Augsburger JJ, et al. Classification and incidence of space-occupying lesions of the orbit. A survey of 645 biopsies. Arch Ophthalmol. 1984;102(11):1606-11.

17. Bullock JD, Goldberg SH, Rakes SM. Ophthalmic Plast Reconstr Surg.1989;5(1):13-6.

18. Moss MH: Expanding lesions of the orbit: A clinical study of 230 consecutive cases. Am J Ophthalmol. 1962;54:761-770.

19. Shields JA, Bakewell B, Augsburger JJ, et al. Spaceoccupying orbital masses in children. A review of 250 consecutive biopsies. Ophthalmology. 1986; 93:379-384.

20. Wright JE, McNab AA, McDonald WI. Optic nerve glioma and the management of optic nerve tumours in the young. Br J Ophthalmol. 1989; 73:967-74.

21. Patel R, Mukherjee B. Mesenchymal chondrosarcoma of the orbit. Orbit. 2012 Apr;31(2):126-8

22. Margo CE, Mulla ZD. Malignant tumors of the orbit. Analysis of the Florida cancer registry. Ophthalmology. 1998;105(1):185-90.

23. Koopman JH, van der Heiden-van der Loo M, Van Dijk $\mathrm{MR}$, et al. Incidence of primary malignant orbital tumors in the Netherlands. Eye (Lond). 2011; 25(4): 461-5.

24. Porterfield JF. Orbital tumors in children. A report on 214 cases. Int Ophthalmol Clin. 1962;2:319-35.

25. Youssefi B. Orbital tumors in children: a clinical study of 62 cases. J Pediatr Ophthalmol. 1969;6:177-81.

26. Liaricos S, Gekas L. Orbital tumors in children. Orbit. 1984;3:25-31.

27. Kodsi SR, Shetlar DJ, Campbell J, et al. A review of 340 orbital tumors in children during a 60-year period. Am J Ophthalmol. 1994;117:177-82.

28. Munirulhaq K. Orbital tumors in children. Orbit. 1989;8:215-22.

29. Demirci H, Shields CL, Shields JA, et al. Orbital tumors in the older adult population. Ophthalmology. 2002; 109: 243-248.

30. Shinder R, Al-Zubidi N, Esmaeli B. Survey of orbital tumors at a comprehensive cancer center in the United States. Head Neck. 2011;33:610-4.
31. Templeton AC. Orbital tumors in African children. Br J Ophthalmol. 1971;55:254-61.

32. Abiose A, Adido J, Agarwal SC. Childhood malignancies of the eye and orbit in Northern Nigeria. Cancer. 1985:15;55(12):2889-93.

33. Moeloek NF, Akman SM, Syukur BA, et al. Retrobulbar tumors in Indonesia. Orbit. 1987;:267-74.

34. Johnson TE, Senft SH, Nasr AM, et al. Pediatric orbital tumors in Saudi Arabia. Orbit 1990; 9:205-15.

35. El-Naggar AM, El-Desouky MA, Shalaby S: Ten years survey of orbital lesions in Tanta. Bull Ophthalmol Soc Egypt, 85: 15-20. 1993.

36. Gunalp I, Gunduz K. Pediatric orbital tumors in Turkey. Ophthalmic Plast Reconstr Surg. 1995;11(3):193-9.

37. Rahman M A, Azad SA, Islam N, et al. CT-Scan Findings of Orbital Mass Among Pediatric Patients at a Tertiary Care Hospital in Bangladesh. AKMMC J. 2017;8(1) : $17-23$.

38. McCarty CS, Brown DN. Orbital tumors in children. Clin Neurosurg. 1964;11:76-93.

39. Venugopal M, Sagesh M. Proptosis. The ENT Surgeon's Perspective. Indian J Otolaryngol Head Neck Surg. 2013;65:247-50.

40. Mafee MF, Putterman A, Valvassori GE, et al. Orbital space occupying lesions: role of computed tomography and magnetic resonance imaging. An analysis of 145 cases. Radiol Clin North Am. 1987;25(3):529-59.

41. Eldrup-Jorgensen P, Fledelius H: Orbital tumors in infancy: an analysis of Danish cases from 1943 to 1962. Acta Ophthalmol. 1975;53:887-93.

42. Illif WJ, Green WR (1978). orbital tumors in children. In: Jakobiec FA, ed. Ocular and adnexial tumors. Birmingham: Aesculapius. Pp. 669-84.

43. Shields JA, Kaden IH, Eagle RC, et al. Orbital dermoid cysts: clinicopathologic correlations, classification, and management. Ophthal Plast Reconstr Surg. 1997; 13:265-76.

44. Shields JA (1989). Cystic lesions of the orbit. In: Diagnosis and management of orbital tumors. Philadelphia, 17 Saunders, Pp. 89-122.

45. Doxanas MT, Green WR, Arentsen JJ, et al: Lid lesions of childhood. A histopathologic survey at the Wilmer Institute (1923-1974). J Pediatr Ophthalmol. 1976;13: 7-39.

46. Bilaniuk LT. Vascular lesions of the orbit in children. Neuroimag Clin North America 2005;15(1):107-20.

47. Shields JA (1989). Vasculogenic tumors and malformations. In: Diagnosis and management of orbital tumors. Philadelphia, Saunders: Pp. 123-148.

48. Iliff WJ, Green WR. Orbital Iymphangiomas. Trans Am Acad Ophthalmol Otolaryngol. 1979;86:914-29.

49. Eiferman RA, Gushard RH. Chocolate Cysts of the orbit. Ann Ophthalmol. 1986;18:156-157.

50. Dryden RM, Wulc AE, Day D. Eyelid ecchymosis and proptosis in Iymphangioma. Am J Ophthalmol. 1985;100:486-87. 
51. Graeb DA, Rootman J, Robertson WD, et al. Orbital lymphangiomas: clinical, radiologic and pathologic considerations. Radiology. 1990;175:417-21.

52. Jones IS, Desjardins L (1973). Management of orbital neurofibromatosis and lymphangiomas. In: Jakobiec FA, ed. Ocular and adnexal tumors. Birmingham: Aesculapius, Pp. 735-40.

53. Wilson ME, Parker PL, Havis RM. Conservative management of childhood orbital lymphangioma. Ophthalmology.1989;96: 484-90.

54. Razek AA, Elkhamary S, Mousa A. Differentiation between benign and malignant orbital tumors at 3-T diffusion MR-imaging. Neuroradiology. 2011;53(7):51722.

55. Machado I, Mayordomo AE, Giner F, et al. The Role of Immunohistochemistry in Rhabdomyosarcoma Diagnosis Using Tissue Microarray Technology and a Xenograft Model. Fetal Pediatr Pathol. 2015; 34(5): 271-81.

56. Andrade CR., Takahama Junior A, Nishimoto IN, et al. Rhabdomyosarcoma of the head and neck: a clinicopathological and immunohistochemical analysis of 29 cases. Braz Dent J. 2010;21:68-73.

57. Raney RB, Maurer HM, Anderson JR, et al. The Intergroup Rhabdomyosarcoma Study Group (IRSG): major lessons from the IRS-I through IRS-IV studies as background for the current IRS-V treatment protocols. Sarcoma. 2001;5:9-15.

58. Raney RB, Walterhouse DO, Meza JL, et al. Results of the intergroup rhabdomyosarcoma study group D9602 protocol, using vincristine and dactinomycin with or without cyclophosphamide and radiation therapy, for newly diagnosed patients with low-risk embryonal rhabdomyosarcoma: a report from the soft tissue sarcoma committee of the children's oncology group. J Clin Oncol. 2011;29:1312-8.

59. Shields JA (1989). Optic nerve and meningeal tumors. In: Diagnosis and management of orbital tumors. Philadelphia, Saunders, Pp. 170-91.

60. Alvord EC, Lofton S. Gliomas of the optic nerve or chiasm. Outcome by patients' age, tumor site, and treatment. J Neurosurg. 1988;68(1):85-98.

61. Nicolin G, Parkin P, Mabbott D, et al. Natural history and outcome of optic pathway gliomas in children. Pediatr Blood Cancer. 2009; 53(7):1231-7.

62. Parsa CF, Hoyt CS, Lesser RL, et al. Spontaneous regression of optic gliomas: thirteen cases documented by 18 serial neuroimaging. Arch Ophthalmol. 2001;119(4): 516-29.

63. Glaser JS (1977). Gliomas of the anterior visual pathways in childhood: Rationale for conservative management. In Brockhurst RJ, Boruchoff SA, Hutchinson BT, et al (eds.): Controversy in Ophthalmology. Philadelphia, W.B. Saunders Co., Pp. 897-906.

64. Thomas RP, Gibbs IC, Xu LW, et al. Treatment options for optic pathway gliomas. Curr Treat Options Neurol. 2015;17(2):333.
65. Goodden J, Pizer B, Pettorini B, et al. The role of surgery in optic pathway/hypothalamic gliomas in children. J Neurosurg Pediatr. 2014;13(1):1-12.

66. Horwich A, Bloom HJG: Optic gliomas: Radiation therapy and prognosis. Int Rad Oncol Biol Phys. 1985;11:1067-79.

67. Montgomery AB, Griffinn T, Parker RG, et al. Oplic nerve glioma: The role of radiation therapy. Cancer. 1980;40:2079-2080.

68. Moreno L, Bautista F, Ashley S, Duncan C, Zacharoulis S. Does chemotherapy affect the visual outcome in children with optic pathway glioma? A systematic review of the evidence. Eur J Cancer. 2010;46(12):2253-9.

69. Avery RA, Hwang EI, Jakacki RI, et al. Marked recovery of vision in children with optic pathway gliomas treated with bevacizumab. JAMA Ophthalmol. 2014;132(1):1114.

70. Stern J, Digiacinto GV, Housepian EM. Neurofibromatosis and optic glioma. Clinical and morphological correlations. Neurosurgery. 979;4:524-8.

71. Lewis RA, Gerson LP, Axelson KA, Riccardi VM, Whitford RP. von Recklinghausen neurofibromatosis. II. Incidence of optic gliomata. Ophthalmology. 1984; 91(8): 929-35.

72. Pilling RF, Taylor RH. Screening children with NF1 for optic pathway glioma. Eye (Lond). 2010;24(9): 1432-4.

73. Shields JA (1989). Peripheral nerve tumors of the orbit. In: Diagnosis and management of orbital tumors. Philadelphia, Saunders, Pp. 149-69.

74. Mulvihill JJ. Background and biologic perspective. In Mulvihill JJ, moderator. Neurofibromatosis 1(Recklinghausen disease) and neurofibromatosis 2 (bilateral acoustic neurofibromatosis): an update. Ann Intern Med. 1990;113:39-52.

75. Li H, Liu $\mathrm{T}$, Chen $\mathrm{X}$, et al. A rare case of primary congenital glaucoma in combination with neurofibromatosis 1: A case report. BMC Ophthalmol. 2015;15:149.

76. Abdallah AM. Recent Decreasing Frequency of Enucleation for Intraocular Retinoblastoma in Upper Egypt. Saudi J Ophthalmol. 2006;20(3):168-75.

77. Walinjkar J, Krishnakumar S, Gopal L, et al. Retinoblastoma presenting with orbital cellulitis. J AAPOS. 2013;17(3):282 -6.

78. Nalcı H, Gündüz K, Erden E. Necrotic intraocular retinoblastoma associated with orbital cellulitis. Surv Ophthalmol. 2018;63(1):114-8.

\section{*Correspondence to:}

Ahmad Mostafa Abdallah

Ophthalmology Department

Sohag Faculty of Medicine

Sohag University, Egypt

Tel: +201063591056

E-mail: Ahmadophth@yahoo.com 